\title{
Time Course of the Development of Pre- and Postjunctional Supersensitivity in the Rabbit Ear Artery after Decentralization
}

\author{
Hiromichi TSURU and Toshihiko UEMATSU* \\ Department of Pharmacology. Hiroshima University School of Medicine. \\ Hiroshima 734, Japan \\ * Department of Pharmacology. Hamamatsu University School of Medicine. \\ Hamamatsu 431-31, Japan \\ Accepted October 19, 1985
}

\begin{abstract}
Changes in the sensitivity of the rabbit ear artery to exogenous norepinephrine and potassium and to sympathetic nerve electrical stimulation were examined in vitro following decentralization which was performed by removing the unilateral preganglionic nerve proximal to the superior cervical ganglion. The contralateral side was left intact as a control. The postjunctional supersensitivity to exogenous norepinephrine and potassium had fully developed one week after the decentralization and was sustained for at least 8 weeks; the arteries decentralized for 1-8 weeks were about 2.1- and 1.3-fold supersensitive to norepinephrine and potassium, respectively, as compared with the contralateral control arteries. The frequency-response curve of the electrically stimulated decentralized artery shifted gradually to the left of the control within weeks after decentralization. Since the response to electrical stimulation was attributed to endogenous norepinephrine released from the sympathetic nerve terminals within the adventitial-medial junction, the leftward shift of the frequency-response curve in the decentralized artery probably reflects a gradual increase in the released norepinephrine per pulse by electrical stimulation, i.e., the prejunctional supersensitivity to electrical stimulation. It is concluded that the prejunctional sympathetic supersensitivity to electrical stimulation develops slower than the postjunctional nonspecific supersensitivity in the rabbit ear artery. The change in the sensitivity of the denervated postganglionic neuron, including the superior cervical ganglion is also discussed with regard to the "law of denervation supersensitivity".
\end{abstract}

Postjunctional supersensitivity following interruption of impulse traffic in various smooth muscles has been well documented (see reviews 1, 2). However, little is known of the prejunctional changes of the postganglionic neuron after decentralization, i.e., preganglionic denervation.

Our previous studies suggested that chronic decentralization (for 8 weeks) of the rabbit ear artery produced not only postjunctional supersensitivity to exogenous norepinephrine (3) and potassium (4) but also prejunctional supersensitivity to electrical stimulation (5). In the present paper, "prejunctional supersensitivity" refers to neuronal hyperreactivity, since it is reasonable that the term be restricted to mean supersensitivity phenomenon occurring in the prejunctional site. Although the conventional use of the term "prejunctional supersensitivity" seems to pertain to the loss of neuronal norepinephrine uptake (i.e., a cocaine-like potentiation, see review 6), this type of supersensitivity seems to occur in the postjunctional effector and not in the pre-junctional site.

The present study was undertaken to further clarify the prejunctional supersensitivity separate from the postjunctional one, by comparing time courses of the change in sensitivity to electrical stimulation and to exogenous norepinephrine. The sensitivity to potassium was also examined, since post- 
junctional nonspecific supersensitivity has been shown to involve altered electrophysiological properties such as partial depolarization of the effector cell membrane $(1,2)$ and potassium produces contraction of vascular tissue, mainly through depolarization (7).

Our results clearly differentiate different time courses in the development of prejunctional supersensitivity to electrical stimulation and the postjunctional supersensitivity to drugs in the decentralized rabbit ear artery. The change in sensitivity of the denervated ganglion will be discussed from the standpoint of prejunctional supersensitivity after decentralization.

\section{Materials and Methods}

Sympathetic decentralization: The decentralization operation was performed on male Japanese white rabbit weighing $2.0-2.3 \mathrm{~kg}$. 1, 2, 4 and 8 weeks prior to in vitro experiments. Following sedation with chlorpromazine $(10 \mathrm{mg} / \mathrm{kg}$, i.m.), the animals were anaesthetized by giving an intraperitoneal injection of a mixture containing per $100 \mathrm{ml}$ : $4.25 \mathrm{~g}$ chloral hydrate, $0.97 \mathrm{~g}$ pentobarbital sodium, $2.13 \mathrm{~g}$ magnesium sulfate. $42.8 \%$ propylene glycol and $11.5 \%$ alcohol. The dose used was about $2 \mathrm{ml} / \mathrm{kg}$ (8). The central artery of the ear was decentralized unilaterally by dissecting the preganglionic fiber $2-3 \mathrm{~cm}$ in length up to the superior cervical ganglion. under sterile conditions. The contralateral ear artery was left intact and served as the control.

Arterial preparations: The animal was killed by a blow on the head and rapid exsanguination. Both decentralized and contralateral control ear arteries were cut in situ, using parallel blades separated by $3 \mathrm{~mm}$. Griffith et al. (9) found that the innervation in the proximal region was about twice as dense as that in the distal region. In this regard, the region used in the present study was consistently the proximal one. The ring segments were cleaned under a dissecting microscope and suspended in tissue baths containing $50 \mathrm{ml}$ of modified Krebsbicarbonate solution aerated with $95 \% \mathrm{O}_{2}+5 \%$ $\mathrm{CO}_{2}$ and maintained at $37^{\circ} \mathrm{C}$. The composition of the modified Krebs-bicarbonate solution in $\mathrm{mM}$ was: $\mathrm{NaCl}, 119 ; \mathrm{KCl}, 4.7 ; \mathrm{CaCl}_{2}, 2.5$;
$\mathrm{KH}_{2} \mathrm{PO}_{4}, 1.2 ; \mathrm{MgSO}_{4}, 1.2 ; \mathrm{NaHCO}_{3}, 25.0$ and glucose, 11.1. A resting tension of $1.0 \mathrm{~g}$ was applied. During the $2 \mathrm{hr}$ equilibration period, the bathing media was renewed approximately every $20 \mathrm{~min}$.

Recording methods of vascular responses: Isometric tension development was recorded on ink-writing oscillographs (Nihon Kohden Kogyo, Tokyo, model RJG-4004 and Watanabe Recording Instruments, Tokyo, model WTR 281) by means of force displacement transducers (Nihon Kohden Kogyo. SB-1T and Kyowa Electronic Instruments, Tokyo, 120T-10B)

Responses to norepinephrine and potassium: In previous studies on the comparison of sensitivity to exogenous norepinephrine among the normal, denervated and decentralized ear arteries $(3,8)$, we added ancillary agents in order to eliminate the interaction of norepinephrine with $\beta$ adrenoceptors, and neuronal and extraneuronal uptakes, focusing on the postsynaptic $\alpha$-adrenoceptor sensitivity (10. 11). However, no such blocking agents were used in the present study since decentralization does not affect uptake and retention in adrenergic nerve terminals (12). Concentration-response curves for norepinephrine were obtained in a cumulative manner (8).

Although use of a high potassium solution to investigate the effect of potassium on smooth muscles is debatable, the sensitivity to potassium with hypertonic high $\mathrm{KCl}$ solution was virtually identical to that obtained with hypertonic high $\mathrm{K}_{2} \mathrm{SO}_{4}$ or with isotonic high potassium solution, and the possible release of norepinephrine from the sympathetic nerve terminals by high potassium was negligible (4). Thus, concentration-response curves for potassium were also obtained by cumulative administration of $2 \mathrm{M} \mathrm{KCl}$ solution into the tissue bath, in the absence of $\alpha$ - and $\beta$-adrenoceptor antagonists.

On the basis of cumulative concentrationresponse curves, the mean median effective concentration $\left(E_{50}\right)$ was calculated geometrically (13).

Responses to transmural electrical stimulation: The contractile response to transmural electrical stimulation was elicited from an 
electronic stimulator (Nihon Kohden Kogyo. MSE-3) by using rectangular pulses of 0.2 msec duration and a supramaximal voltage of 40-50 $\mathrm{V}$ between platinum electrodes placed on either side of the artery $(5,8)$. An electrical stimulation frequency-response curve was obtained by a random order of stimulation frequency. The stimulation intervals were 15-20 min. The response was reproducible for more than 10 times under these conditions.

There has been no consistent handling of the frequency-response curve, e.g., some are plotted on an arithmetic scale (14) and others, on a log scale (15). In the present study, the median effective frequency $\left(E_{50}\right)$ was obtained from the frequency-response curve plotted on a log scale of frequency as the abscissa, and the mean $E_{50}$ 's and the statistical tests of their significance were made on the basis of the geometric means (see Results).

Chemical agents: Drugs used were norepinephrine bitartrate (I-Arterenol bitartrate. Sigma), tetrodotoxin (Sankyo), cocaine hydrochloride (Takeda), phentolamine mesylsulfonate (Ciba Geigy), prazosin hydrochloride (Pfeizer), dl-propranolol hydrochloride (Inderal, $\mathrm{ICl}$ ), chlorpromazine (Wintermin, Shionogi), and pentobarbital sodium (Tokyo Kasei). The former five agents were dissolved in distilled water as stock solutions and frozen. The stock solutions were thawed and diluted with $0.9 \% \mathrm{NaCl}$ solution into appropriate concentrations before each experiment.

Statistical analysis: Decentralized and control arterial ring segments were considered paired if they were removed from the same animal and were tested during the same time period. Statistical evaluation of the results was made using Student's t-test of paired. when applicable, or unpaired samples. The 0.05 level of probability was regarded as significant.

\section{Results}

Responses to exogenous norepinephrine and poiassium: Development of postjunctional supersensitivity: Norepinephrine concentration-response curves of control and decentralized vessel rings from the 1 week decentralization group are shown in
Fig. 1. The maximum developed force was similar in the control and the decentralized vessels. The decentralized vessel, however, was 2.1 -fold more sensitive to norepinephrine than was the control. The mean $E_{50}$ values for norepinephrine are summarized in Table 1, together with 95\% confidence intervals.

The increases in sensitivity to norepinephrine in the decentralized vessel ranged from 2.1- to 2.4-fold throughout different terms of decentralization, and no significant difference was observed with these ratios (Table 1 and Fig. 7). Mean $E_{50}$ values for norepinephrine in the presence of propranolol $\left(3 \times 10^{-6} \mathrm{M}\right)$, desipramine $\left(3 \times 10^{-7} \mathrm{M}\right)$ and hydrocortisone $\left(8.7 \times 10^{-6} \mathrm{M}\right)$, which were used to eliminate the interaction of norepinephrine with $\beta$-adrenoceptors, neuronal and extraneuronal uptakes, 8 weeks after decentralization (cited from ref. 8), are also shown in Table 1. The data indicate that the decentralized vessel was 2.65-fold more

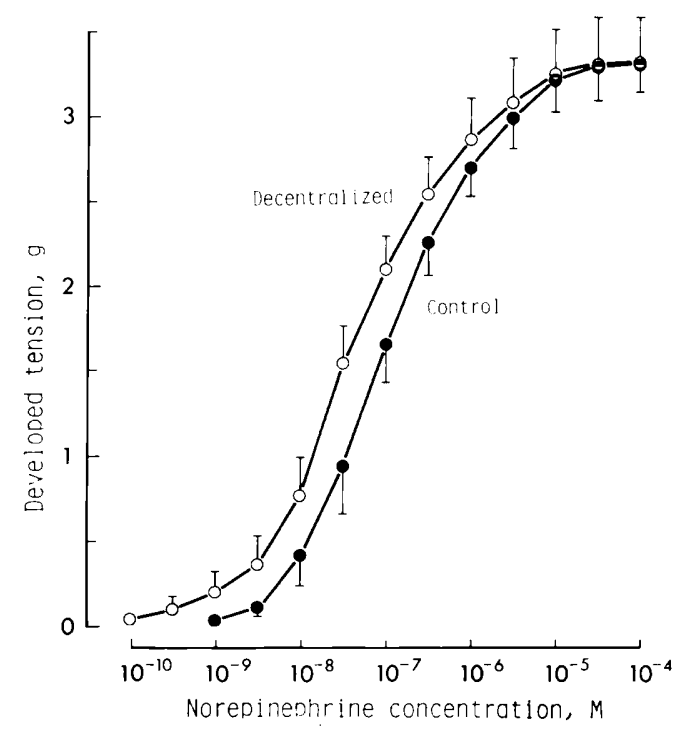

Fig. 1. Concentration-response curves for norepinephrine in decentralized (for 1 week) and corresponding control arteries $(n=7)$. Ordinate shows the tension development and vertical bars represent S.E. The decentralized artery developed significantly larger tension than the control, at concentration ranges $3 \times 10^{-10}-10^{-6} \mathrm{M}(\mathrm{P}<0.02$, paired $t$-test $)$. while the maximum developed tensions were practically the same. 


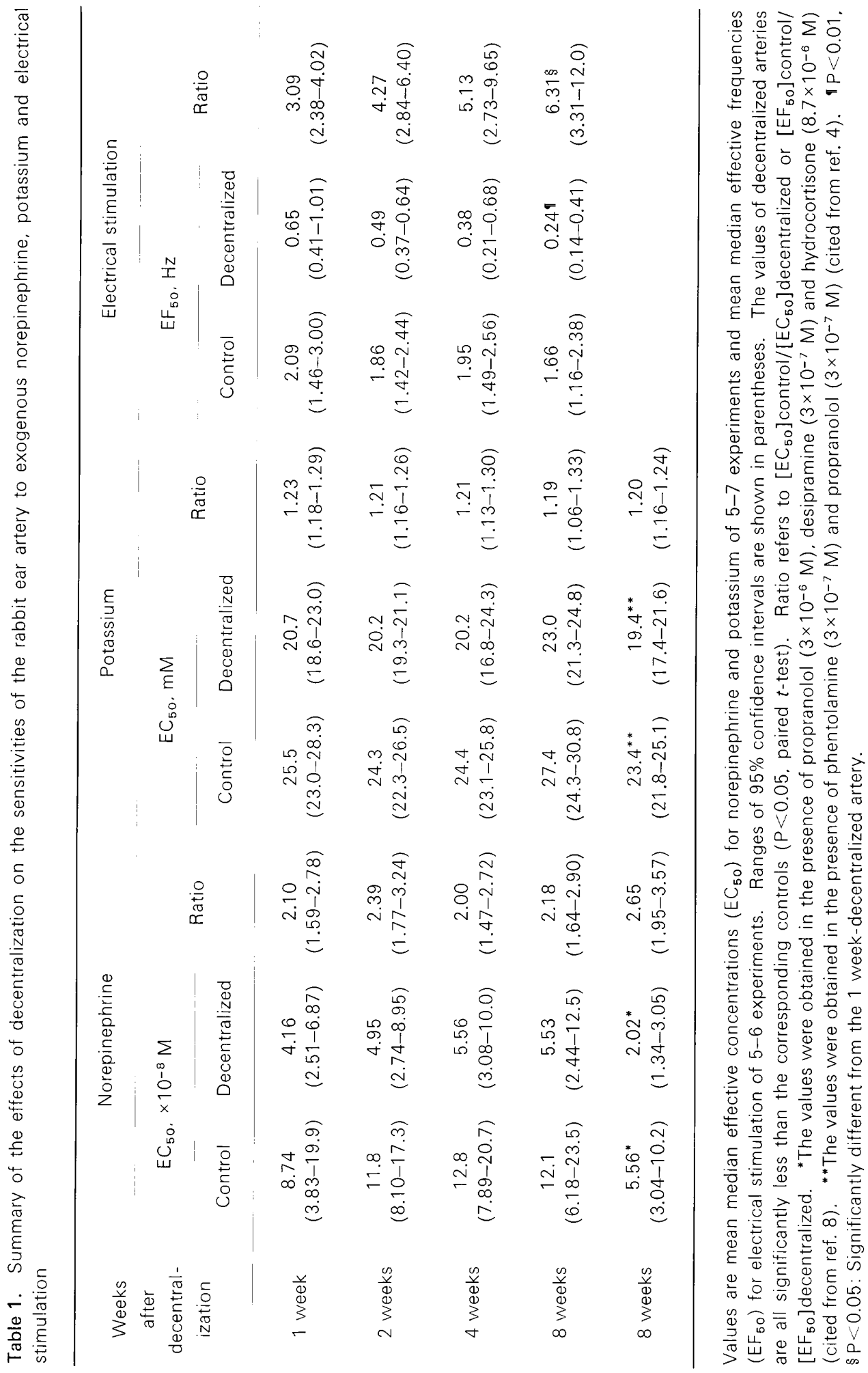


sensitive than the control. Comparing the data obtained in the presence and in the absence of these ancillary drugs with 8 weeks after decentralization (Table 1), the former values are reasonably less than the latter values, both in the control and decentralized vessels, but there is no significant difference in the degree of supersensitivity, thereby suggesting that decentralization supersensitivity does not depend upon alterations in the $\beta$-adrenoceptor sensitivity, neuronal and extraneuronal uptake mechanisms. The inference is in accord with the conclusion of Cervoni et al. (12).

The concentration-response curve of the decentralized artery for hypertonic high potassium also shifted to the left of the control (Fig. 2). There was no significant difference in the maximum response between the control and the decentralized vessels. The increase in sensitivity to potassium in the decentralized vessels also seemed to be very stable throughout different terms of decentralization. ranging from 1.19 - to 1.23 -fold at $E_{50}$ (Table 1 and Fig. 7). Mean $E_{50}$ values obtained in the presence of the $\alpha$-adrenoceptor antagonist phentolamine at $3 \times 10^{-7}$ $\mathrm{M}$ and the $\beta$-adrenoceptor antagonist propranolol at $3 \times 10^{-7} \mathrm{M}$, cited from our previous paper (4), are also shown in Table 1 . The values are consistent with the present results that involvement of the norepinephrine released from the nerve terminals by potassium might be negligible under these experimental conditions.

Response to electrical stimulation: Development of prejunctional supersensitivity: Both control and decentralized ear arteries contracted frequency-dependently in response to electrical field stimulation. As shown in Fig. 3, the tension development reached the approximate maximum usually within 480 pulses of electrical stimulation at frequencies of $4 \mathrm{~Hz}$ or less. Therefore, the stimulation was stopped within 480 pulses whenever the tension development seemed to have reached a plateau. At $8 \mathrm{~Hz}$ or more, although 480 pulses were not sufficient to elicit the maximum response, producing more than $95 \%$ of the maximum, the stimulation was also applied up to 480 pulses in these cases.

The decentralized artery responded to

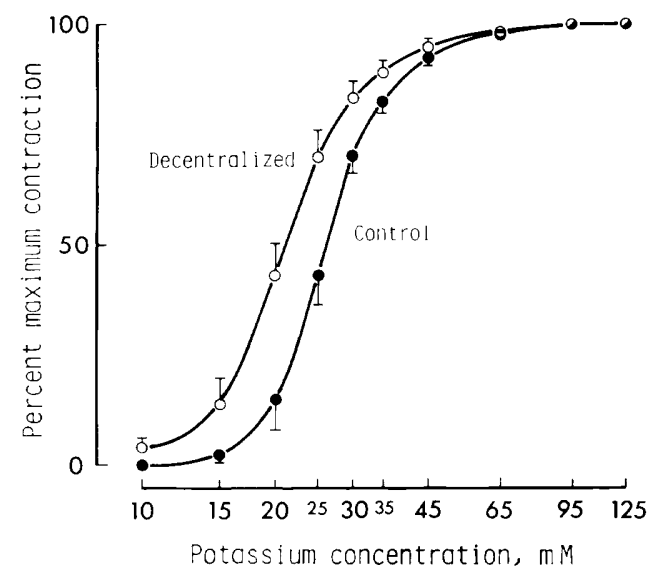

Fig. 2. Concentration-response curves for potassium in decentralized (for 1 week) and corresponding control arteries $(n=7)$. There was no significant difference in the maximum response to potassium between the decentralized and control arteries. Ordinate shows the percent of the maximum response.

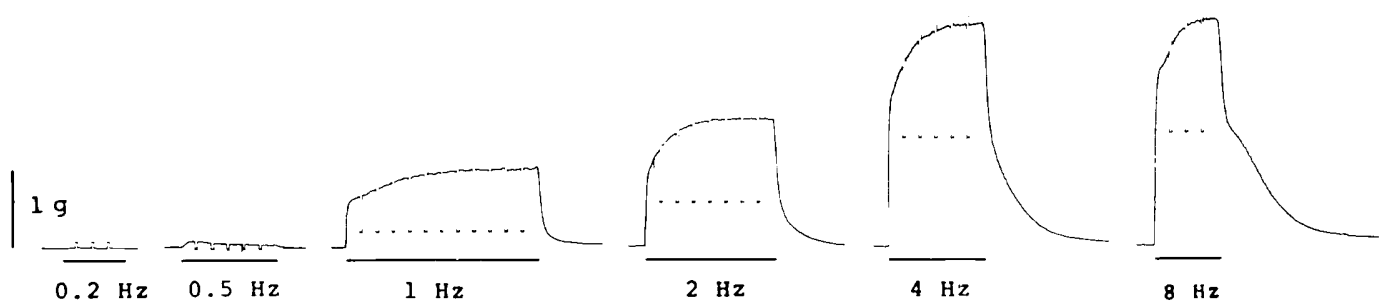

Fig. 3. Time course of the tension development in response to various frequencies of electrical stimulation. The control ear artery obtained from a 2 weeks-decentralized rabbit was stimulated using 0.2 msec duration, supramaximal voltage. During the electrical stimulation (shown by horizontal thick lines), recording was interrupted every $30 \mathrm{sec}$, for convenience of time scale. 


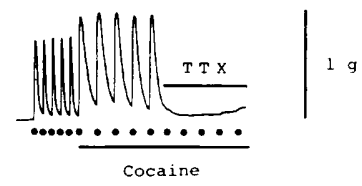

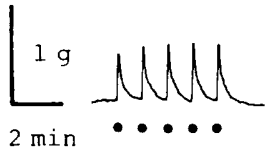

$1 / 60 \mathrm{~Hz}$

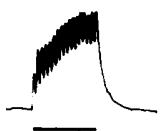

$0.1 \mathrm{~Hz}$

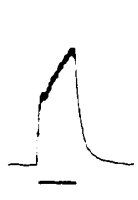

$0.2 \mathrm{~Hz}$

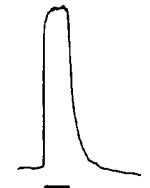

$0.5 \mathrm{~Hz}$

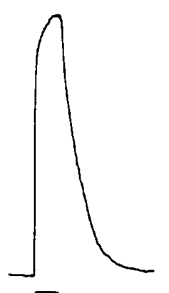

$1 \mathrm{~Hz}$

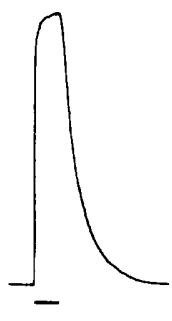

$2 \mathrm{~Hz}$

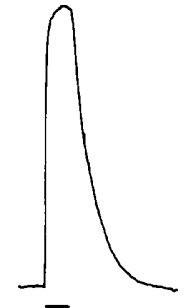

$4 \mathrm{~Hz}$

Fig. 4. Typical recording of contractile responses of the decentralized ear artery (for 2 weeks) to electrical stimulation. The condition of electrical stimulation was the same as in Fig. 3 . Note that the decentralized artery responds to very low frequencies and that the rapid phasic contractile response to a single pulse stimulation is manifest. In the inset, after the decentra!ized artery was stimulated (shown by dots) at every $1 \mathrm{~min}$, the twitch-like response was enhanced, and the decline of contraction was inhibited in the presence of cocaine $10^{-5} \mathrm{M}$. Therefore, the artery was stimulated every 2 min. Tetrodotoxin $\left(3 \times 10^{-8} \mathrm{M}\right)$ abolished the response.

lower frequencies of stimulation, as compared with the control (Fig. 4). It also became obvious that the artery with a long-term decentralization responded to single pulse stimulation (actually, $1 / 60 \mathrm{~Hz}$ ). This rapid phasic contraction (twitch-like response) developed slowly and gradually after decentralization. As shown in the inset of Fig. 4, the twitch-like response was abolished by a low concentration $\left(3 \times 10^{-8}\right.$ $\mathrm{M})$ of tetrodotoxin and was conversely enhanced by cocaine $\left(10^{-5} \mathrm{M}\right)$. The twitchlike response was abolished by the $\alpha$ adrenoceptor antagonist phentolamine $\left(10^{-6}\right.$ $\mathrm{M})$ or prazosin $\left(10^{-8} \mathrm{M}\right)$. Likewise, responses to higher stimulation frequencies were also depressed by the $\alpha$-adrenoceptor antagonists. In addition, when the concentration of $\mathrm{Ca}$ in the bathing media was lowered to $1 / 2$ or $1 / 4$ of that in the normal media, twitch-like responses as well as tetanic responses of both control and decentralized arteries diminished extremely. Ca-free media abolished the response to electrical stimulation.

When the magnitude of response is plotted versus the logarithm of electrical stimulation frequency, a sigmoidal curve results (Fig. 5), i.e., the response seems to be related to geometric increment in frequency. There was no significant difference in the frequencyresponse curves among the control artery groups of $1,2,4$ and 8 weeks after decen-

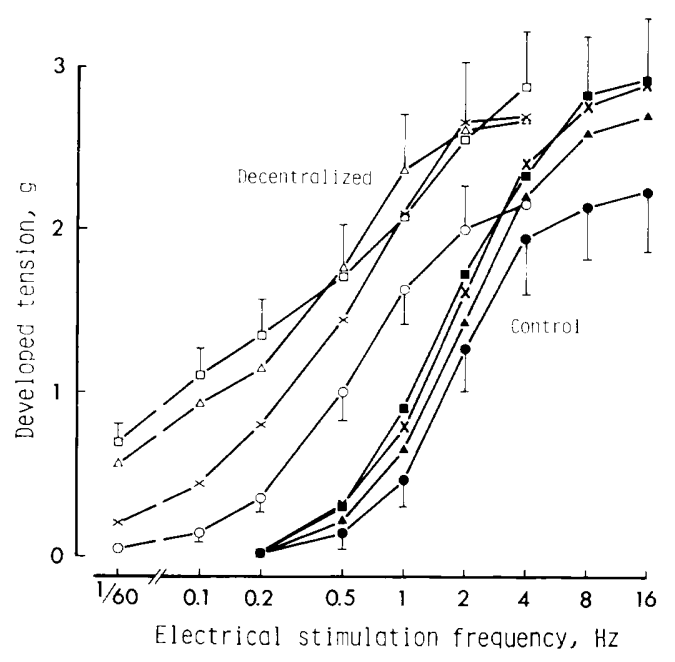

Fig. 5. Mean electrical stimulation frequencyresponse curves. The mean curve was obtained from 5-6 individual curves which were obtained in random order of various frequencies of electrical stimulation. $\bigcirc, \times, \Delta$ and $\square$ : arteries decentralized for 1, 2, 4 and 8 weeks, respectively;,$\times, \mathbf{\Delta}$ and $\square$ : corresponding control arteries. Vertical bars represent the S.E. Control curves were not significantly different. Note that the curves of decentralized arteries shifted to the left with time after decentralization.

tralization (Fig. 5). On the other hand, the stimulation frequency-response curves of the decentralized arteries shifted to the left of the 
A

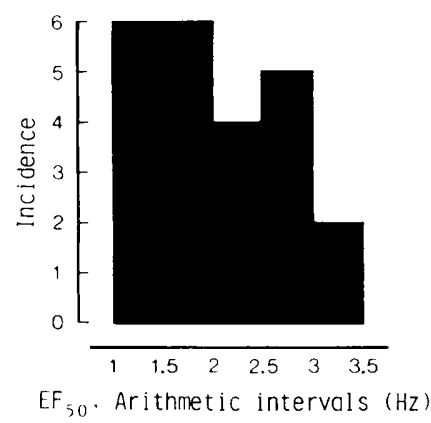

B

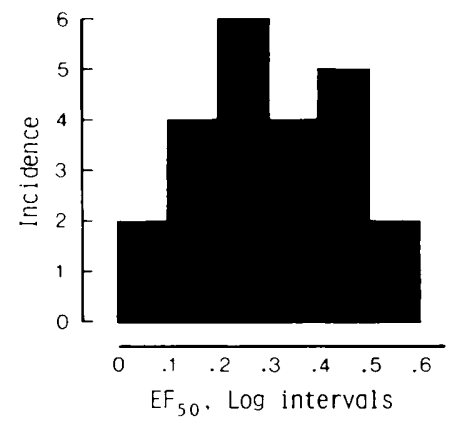

Fig. 6. Histograms of the arithmetic (A) and logarithmic (B) distribution of median effective frequencies $\left(E F_{50}\right)$ of electrical stimulation in the control rabbit ear artery. $\mathrm{N}=23$, range of $E F_{50}$ values: 1.19 to 3.31 $\mathrm{Hz}$, range of logs: 0.08 to 0.52 . Arithmetic and logarithmic means of $E F_{50}$ together with their $95 \%$ confidence intervals (in parentheses) were $2.08 \mathrm{~Hz}(1.81-2.35)$ and $1.98 \mathrm{~Hz}(1.85-2.12)$, respectively.

control. The degrees of the leftward shift became more prominent with time after decentralization (Fig. 5).

The $\mathrm{EF}_{50}$ histograms were made on both arithmetic and logarithmic scales, as shown in Fig. 6, using the data of control ear arteries obtained from the rabbits decentralized for 1 , 2, 4 and 8 weeks. D values denoting the maximum deviation from the KolmogorovSmirnov test (16) were 0.12 for arithmetic and 0.08 for $\log$ values. There was no significant deviation from the normal distribution of the arithmetic as well as the log values $(P>0.2$ in both cases). However, on an arithmetic scale, the values were rather skewed toward the left, in contrast to the distribution of $\log E F_{50}$ values which appeared normal (Fig. 6). Thus, it seems reasonable that the mean $E F_{50}$ 's and statistical tests of their significance are made on the basis of the geometric means.

There was no significant difference in mean $\mathrm{EF}_{50}$ values among the control artery groups obtained from different terms of decentralization (Table 1). The $\mathrm{EF}_{50}$ values of decentralized arteries were, however, significantly less than those of respective control arteries. The $\mathrm{EF}_{50}$ values of decentralized arteries decreased with weeks after decentralization, and the values from 8 weeksdecentralized animals were significantly less than those in case of a 1 week-decentralization (Table 1). Thus, the ratio of $\left[E F_{50}\right]$ control / $\left[E F_{50}\right]$ decentralized, which

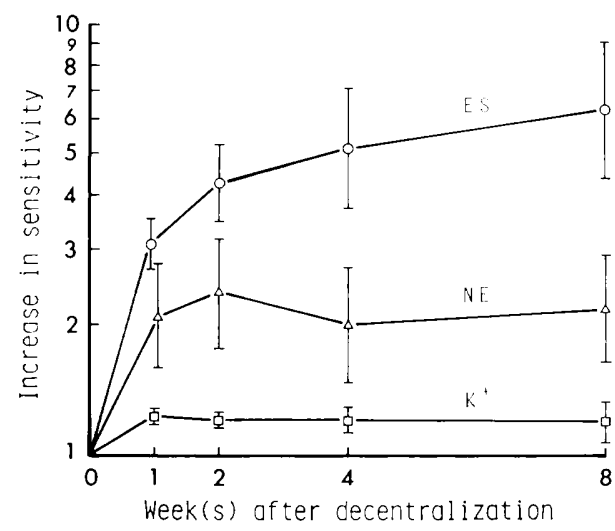

Fig. 7. Time course of the development of supersensitivity to electrical stimulation (ES), norepinephrine (NE) and potassium $\left(\mathrm{K}^{+}\right)$in the decentralized artery. Ordinates: increase in sensitivity (expressed as antilog of $\left(\log \left[\mathrm{EC}_{50}\right]\right.$ or $\left[E F_{50}\right]$ control-log $\left[E C_{50}\right]$ or $\left[E F_{50}\right]$ decentralized). Each point shows the geometric mean ratio of median effective frequencies or median effective concentrations of control vs. decentralized arteries. Vertical bars represent S.E. Only one point of ES at 8 weeks was significantly larger than that at 1 week $(P<0.05)$.

might reflect the degree of prejunctional supersensitivity, increased gradually, and the value of 8 weeks-decentralized artery was significantly larger than that of 1 weekdecentralized artery (Table 1). Figure 7 illustrates time courses of the development of supersensitivity to electrical stimulation as well as to norepinephrine and potassium in 
the decentralized artery.

\section{Discussion}

The present results confirm the suggestion of Tsuru and Bevan (5) that adrenergic nerve terminals within the chronically decentralized rabbit ear artery are supersensitive to electrical stimulation as compared with the normal one, i.e., the former releases more norepinephrine per nerve impulse than the latter. It is also revealed that the development of the sympathetic prejunctional supersensitivity was delayed longer than that of the postjunctional one.

The present and the previous results $(4,8)$ confirm that the response to electrical stimulation under the present experimental conditions is exclusively mediated by endogenous norepinephrine released from the intrinsic sympathetic nerve terminals within the adventitial-medial junction. In addition, it seems likely that neither $r$-receptors (17) nor the co-transmitter ATP $(18,19)$ is involved in the response.

The $\mathrm{EF}_{50}$ values of the decentralized arteries were significantly less than the controls (Table 1). Moreover, while the values of the control seemed to be steady. those of the decentralized artery decreased with weeks after decentralization. Therefore, the mean ratios of $\mathrm{EF}_{50}$ for the control versus $\mathrm{EF}_{50}$ for decentralized arteries, which were also calculated geometrically, tended to increase gradually (Fig. 7). In fact, the mean ratio of the 8 weeks-postoperative group was significantly larger than that of the 1 weekpostoperative group (Table 1, Fig. 7).

On the other hand, the change in sensitivities to exogenous norepinephrine and potassium were also found 1 week after decentralization, and the condition was maintained for 8 weeks (Table 1. Fig. 7). Therefore, it seems likely that the timedependent leftward shift of the frequencyresponse curve and slow development of twitch-like response (Fig. 5) correspond to the increase in the amount of norepinephrine released per nerve impulse. In other words, decentralization results in gradual development of prejunctional supersensitivity to electrical stimulation as compared with the relatively rapid development of postjunctional supersensitivity.

There is accumulating evidence that decentralization is associated with increases in transmitter release from the sympathetic postganglionic nerves in the rat iris (20) and the rat salivary gland (21), which are innervated by the superior cervical ganglion. as is the case with the nictitating membrane, the cat spleen (22), and the guinea-pig and the rat vas deferens (23). Westfall (23) suggested that the gradual loss of activity of $\alpha$-adrenoceptor, muscarinic, and prostaglandin inhibitory presynaptic receptors was involved in these time-dependent increases in the release of ${ }^{3} \mathrm{H}$-norepinephrine and dopamine $\beta$-hydroxylase and an increased response of the postjunctional receptor to electrical stimulation. In particular, the subsensitivity of the presynaptic $\alpha_{2}$ adrenoceptor is responsible for the increment of neurotransmitter release by electrical stimulation after surgical decentralization of the rat salivary gland (21) and the guinea-pig and rat vas deferens (23), after chronic ganglion blockade with chlorisondamine of the guinea-pig and rat vas deferens (14), and after long-term antidepressant desipramine treatment in the rat atrium (15). Therefore, such may be also the case in the present experiment with rabbit ear artery.

Electrophysiological properties of the effector smooth muscle cells may be altered by interruption of sympathetic innervation (see review 2). Partial depolarization is, at least in part, responsible for nonspecific postsynaptic supersensitivity in the guineapig vas deferens (24), the rat portal vein (25) and the rabbit saphenous artery (26). If such is the case in the denervated sympathetic ganglia, it is understandable that the prejunctional adrenoceptors may become subsensitive and the transmitter releases increase, because Brown and Caulfield (27) found that the adrenergic cell bodies in the superior cervical ganglia of the rat were hyperpolarized through activation of the same type of $\alpha$-receptor (i.e., " $\alpha_{2}$-receptor") as present at the adrenergic nerve terminals. Therefore, possible alterations in electrophysiological properties of the denervated ganglia have to be considered.

Decentralization of tissues is usually 
performed by excision of preganglionic fiber, being identical with the denervation of the ganglion. There is controversy as to whether the superior cervical ganglion fits the "law of denervation supersensitivity". Fleming et al. (1) described in their review on the base of Green's experiment (28) that the chronically denervated superior cervical ganglion of the cat was, in fact, subsensitive to both nicotinic and muscarinic drugs as well as potassium. At present, however, Green's inferences (28) seem to be debatable. In his experiment, assessment of the changes in sensitivity in the nictitating membrane was accomplished by determining the frequencyresponse relationship to postganglionic nerve stimulation rather than determining the doseresponse relationship to norepinephrine, because he considered that the activation by electrical nerve stimulation more closely resembled that produced by ganglionic stimulation. While the frequency-response curve to postganglionic nerve stimulation gradually shifted to the left after decentralization, confirming the findings of Langer et al. (29), the sensitivity of the ganglion to acetylcholine remained unchanged during this time period. Thus, he considered that the sensitivity of the ganglion to acetylcholine had actually decreased. However, since decentralization produces time-dependent increases in the release of neurotransmitter by electrical stimulation, the leftward shift of the frequency-response curve after decentralization in the nictitating membrane also may reflect both prejunctional and postjunctional changes. Although, there are methodological problems related to testing the sensitivity of the denervated superior cervical ganglion (see review 1), measurement of alteration in the ganglion cells may yield more reliable data. Brown (22) found no alteration in depolarization of isolated rat or kitten superior cervical ganglia by acetylcholine and carbachol following degenerative sectioning of the preganglionic nerve trunk. The results were obtained with an external moving-fluid electrode system and were not in favor of either notion of supersensitivity or subsensitivity after the denervation.

In conclusion, if we accept the current concept that ganglion transmission is achieved with action potentials induced by preganglionic neurotransmitter acetylcholine (30) and if we accept the abundant results that the transmitter release from sympathetic postganglionic nerve terminals by electrical stimulation increases after preganglionic denervation (i.e., decentralization), it is conceivable that the denervated postganglionic neurons, including the ganglion cell body as well as nerve terminals, would become more excitable, i.e., supersensitive to stimulants. The release of transmitter from the nerve terminals should be measured to confirm directly this idea.

Acknowledgements: We are grateful to the late lamented Dr. Che Su for pertinent discussion.

\section{References}

1 Fleming, W.W., McPhillips, J.J. and Westfall, D.P.: Postjunctional supersensitivity and subsensitivity of excitable tissues to drugs. Ergeb. Physiol. Biol. Chem. Exp. Pharmakol. 68, 55-119 (1973)

2 Westfall, D.P.: Supersensitivity of smooth muscle. In Smooth Muscle: an Assessment of Current Knowledge. Edited by Bülbring, E., Brading, A.F., Jones, A.W. and Tomita, T., p. 285-309, Edward Arnold, London (1981)

3 Bevan, R.D. and Tsuru, H.: Long-term influence of the sympathetic nervous system on arterial structure and reactivity: Possible factor in hypertension. In Disturbances in Neurogenic Control of the Circulation. Edited by Abboud, F.M., Fozzard, H.A., Gilmore, J.P. and Reis, D.J., p. 153-160, American Physiological Society. Bethesda (1981)

4 Tsuru, H., Bevan, R.D. and Shigei, T.: Comparative study of supersensitivity to $\mathrm{K}^{+}$after denervation and decentralization in rabbit ear artery. Eur. J. Pharmacol. 84, 9-16 (1982)

5 Tsuru, H. and Bevan, R.D.: Presynaptic sympathetic supersensitivity following long-term preganglionic denervation. Experientia 36, 968969 (1980)

6 Fleming, W.W.: Variable sensitivity of excitable cells: Possible mechanisms and biological significance. Rev. Neuroscience 2, 43-90 (1976)

7 Droogmans, G., Raeymaekers, L. and Casteels, R.: Electro- and pharmacomechanical coupling in the smooth muscle cells of the rabbit ear artery. J. Gen. Physiol. 70. 129-148 (1977)

8 Bevan, R.D. and Tsuru, H.: Functional and structural changes in the rabbit ear artery after sympathetic denervation. Circ. Res. 49, 478-485 
(1981)

9 Griffith, S.G., Crowe, R., Lincoln, J., Haven, A.J. and Burnstock, G.: Regional differences in the density of perivascular nerves and varicosities, noradrenaline content and responses to nerve stimulation in the rabbit ear artery. Blood Vessels 19, 41-52 (1982)

10 Furchgott, R.F.: The classification of adrenoceptors (adrenergic receptors). An evaluation from the standpoint of receptor theory. In Handbook of Experimental Pharmacology, Supp. Vol. 33, Catecholamines, Edited by Blaschko, H. and Muscholl, E., p. 283-335. Springer-Verlag. Berlin, Heidelberg and New York (1972)

11 Trendelenburg, U.: Factors influencing the concentration of catecholamines at the receptors. In Handbook of Experimental Pharmacology, Supp. Vol. 33, Catecholamines, Edited by Blaschko, H. and Muscholl, E., p. 726-761, Springer-Verlag, Berlin, Heidelberg and New York (1972)

12 Cervoni, P., Reit, E. and McCullough, J.: Studies on the decentralized nictitating membrane of the cat. II. Uptake and retention of norepinephrine and epinephrine. J. Pharmacol. Exp. Ther. 175, 649-663 (1970)

13 Fleming, W.W., Westfall, D.P., de la Lande, I.S. and Jellett, L.B.: Log-normal distribution of equieffective doses of norepinephrine and acetylcholine in several tissues. J. Pharmacol. Exp. Ther. 181, 339-345 (1972)

14 Sax, R.D. and Westfall, T.C.: Alterations in prejunctional adrenoceptor function in guinea-pig and rat vas deferens after chronic ganglionic blockade. J. Pharmacol. Exp. Ther. 219, 21-26 (1981)

15 Crews, F.T. and Smith, C.B.: Presynaptic alphareceptor subsensitivity after long-term antidepressant treatment. Science 202, 322-324 (1978)

16 Siegel, S.: Nonparametric Statistics for the Behavioral Sciences. p. 47-52, McGraw-Hill, New York (1956)

17 Hirst, G.D.S., Neild, T.O. and Siverberg, G.D.: Noradrenaline receptors in the rat basilar artery. J. Physiol. (Lond.) 328, 351-360 (1982)

18 Sneddon, P. and Burnstock, G.: ATP as a cotransmitter in rat tail artery. Eur. J. Pharmacol. 106, 149-152 (1984)

19 Sneddon, P. and Westfall, D.P.: Pharmacological evidence that adenosine triphosphate and noradrenaline are co-transmitters in the guineapig vas deferens. J. Physiol. (Lond.) 347, 561-
$580(1984)$

20 Hamberger, B. and Farnebo, L.-O.: Decentralisation increases noradrenaline release from field-stimulated rat irides. In Frontiers in Catecholamine Research, Edited by Usdin, E. and Snyder, S., p. 615-616. Pergamon Press, New York (1973)

21 Wakade, T.D. and Wakade, A.R.: Presynaptic $\alpha$ receptor-mediated control of norepinephrine release is decreased after chronic decentralization. Pharmacologist 19, 239 (1977)

22 Brown, D.A.: Depolarization of normal and preganglionically denervated superior cervical ganglia by stimulant drugs. Br. J. Pharmacol. 26, 511-520 (1966)

23 Westfall, T.C.: Local regulation of adrenergic neurotransmission. Physiol. Rev. 57, 659-728 (1977)

24 Fleming, W.W. and Westfall, D.P.: Altered resting membrane potential in the supersensitive vas deferens of the guinea pig. J. Pharmacol. Exp. Ther. 192, 381-389 (1975)

25 Aprigliano, O. and Hermsmeyer, K.: Trophic influence of the sympathetic nervous system on the rat portal vein. Circ. Res. 41, 198-206 (1977)

26 Abel, P.W., Urquilla, P.R., Goto, K., Westfall, D.P., Robinson, R.L. and Fleming, W.W.: Chronic reserpine treatment alters sensitivity and membrane potential of the rabbit saphenous artery. J. Pharmacol. Exp. Ther. 217, 430-439 (1981)

27 Brown, D.A. and Caulfield, M.P.: Hyperpolarizing ' $\alpha_{2}$ '-adrenoceptors in rat sympathetic ganglia. Br. J. Pharmacol. 65, 435-445 (1979)

28 Green, R.D., III: The effect of denervation of the sensitivity of the superior cervical ganglion of the pithed cat. J. Pharmacol. Exp. Ther. 167, 143-150 (1969)

29 Langer, S.Z., Draskoczy, P.R. and Trendelenburg, U.: Time course of the development of supersensitivity to various amines in the nictitating membrane of the pithed cat after denervation or decentralization. J. Pharmacol. Exp. Ther. 157, 255-273 (1967)

30 Holman, M.E. and Hirst, G.D.S.: Junctional transmission in smooth muscle and the autonomic nervous system. In Handbook of Physiology, Section 1: The Nervous System, Edited by Brookhart, J.M. and Mountcastle, V.B., Vol. 1, Cellular Biology of Neurons, Part 1. Edited by Kandel, E.R., p. 417-461, American Physiological Society, Bethesda (1977) 